University of Louisville

ThinkIR: The University of Louisville's Institutional Repository

Electronic Theses and Dissertations

1932

\title{
The cause of vascular sclerosis in essential hypertension and related phenomena
}

Claude W. Chappell

University of Louisville

Follow this and additional works at: https://ir.library.louisville.edu/etd

Part of the Circulatory and Respiratory Physiology Commons

\section{Recommended Citation}

Chappell, Claude W., "The cause of vascular sclerosis in essential hypertension and related phenomena" (1932). Electronic Theses and Dissertations. Paper 1695.

https://doi.org/10.18297/etd/1695

This Master's Thesis is brought to you for free and open access by ThinkIR: The University of Louisville's Institutional Repository. It has been accepted for inclusion in Electronic Theses and Dissertations by an authorized administrator of ThinkIR: The University of Louisville's Institutional Repository. This title appears here courtesy of the author, who has retained all other copyrights. For more information, please contact thinkir@louisville.edu. 


\section{UNIVERSITY OF LOUISVILLE}

The Cause of Vascular Sclerosis in Essential Hypertension and Related Phenomena. $v$

\section{A Dissertation}

Submitted to the Faculty

of the Graduate School of the University of Louisville

In Partial Fulfillment of the

Requirements for the Degree

of Master of Science

Department of Pathology and Bacteriology

By

Claude T. Chappell 
The phenomenon of essential hypertension has been attacked apparently from every possible angle, but as yet no conclusive results have been recorded, al tho numerous approaches have elucidated the problem. Since high blood pressure is only a symptom of a disease, one will have to take into consideration all those conditions which are known to be associated with increased tension, such as the mechanical, nervous, chemical, or toxio factors.

The phygiology of the circulation indicates that blood pressure is raised by either an increased cardiac output or decreased peripheral outflow or both. In reviewing the literatare, the theory of increased cardiac output has fielded the least fruitful results. All experimenters do not agree in the minute details, but, in general, it can be said that there is not sufficient increase in cardiac output to account for the enormous pressures which are usualIy recorded. Burwell \& $\operatorname{Smith}(1)$ found that the stroke and minute volumes are not increased in hypertension. Henderson (2) stated that the minute volume increased with a rate up to 120 beats per minute, remains fairly constant up to 240 , but above this the minute volume falls. Moore, Hamilton and Kinsman(3) do not find increased cardiac outputs in hypertension to account for the rise in pressure. The tension that sometimes occurs with tachycardia can be explained by means other than a primary heart action. 
The experiments based on the theory of a decreased peripheral outfl ow are more numerous, and some phases have given quite plausible results. On the assumption that hypertension is produced by a lessened flow of blood thru the arterioles and capillaries, one can imagine several exolanations for it.

Variations of the blood, such as changes in its viscosity or an increase in volume, have been sugested as a cause for high blood pressure. But both clinical experience and experiments have shown these factors to be highly improbable. Austrian (4) found that the viscosity of the blood had little or no relation to elevated pressure, and Keith, Rountree and Geraghty (5), found no'relation between blood rolume and pressure., The latter workers failing in an attempt to raise the pressure by increasing the blood volume accounted for their failure to produce a rise due to marked splanchnic relaxation. The blood bed is capable of holding an enormous quantity over and above its normal capacity. This fact is well illustrated in shock, in which the patient is said to "bleed in his own vessels", It is true, however, that in some patients with hypertension the ingestion of large quantities of water will tend to raise the pressure, but in these cases the regulatory mechanisms, which may have been influenced by arterlolar sclerosis, have al ready been damaged.

Nervous influences can so act as to bring about elevated pressure. Normally the vascular areas of the body 
work in co-ordination, but if any of them become thrown out of order so that a constriction in one place cannot be compensated for in another with dilation an hypertension will result. Nervous impulses may be of reflex or central origin which bring about peripheral vascular constriotion. Those whlch are reflex in origin according to Hering ${ }^{(6)}$ are from the carotid sinus and arch of the aorta. Impulses arising at these points pass to the vasomotor and cardiac centers which in turn pass the impulses to the periphery. The carotid sinus was removed from the regular circulation, and stimulated mechanically by changing perfusion pressure, also electrical stimuli could be made to elicit reflexes similar to those produced by changes in perfusion pressure. In order to show that changes in pressure affect chiefly the carotid ainus Heymang( 7$)$ denervated it, and found the systemic pressure to be little or none changed on clamping and releasIng the carotid arteries. Besides the direct nerve effect it is further shown that there is a reflex secretion of adrenaline. This was proven by cross circulation experiment in dogs. (8)

Besides the carotid sinus and the depressor reflex others are supposed to exist somewhere distal to the bifurcation of the carotid. With this in mind, Florey, Marvin and Drury ${ }^{(9)}$ found in the rabbit, dog and cat that variations in the pressure of the circle of Willis caused a rise or lowering of the general systemic pressure. But these reflexes were not nearly so adequate as those of the carotid sinus. 
A change in pressure of 50-60 mm. Hg. are needed before the reflex is elleited. Nash(10) besides verifying Hering ' $(6)$ claims, also showed that perfusion above the carotid ginus thru the vertebrals, exerted effects quite similar to those of the carotid sinus.

Besides reflex paths beginning along the course of the cerebral vessels there is evidence of a direct effect on the cerebral centers which bring about changes in the general systemic pressure. Starling(II) considered an asphyxial condition of the vasomotor center which stimulated it as an explanation of the anemic blood curve rise. Anrep \& Segall (12) believe that the effect of reduced cerebral pressure can't be explained on the basis of an inadequate blood supply or ischemia since changes in the pressure of not more than 15-20 mm. Hg . have often a considerable effect on heart rate while they have only a small effect on blood flow thru the head. Pressures, as such, then, within the cerebral vessels of the vasomotor centers are of some importance.

Toxic substances passing thru the brain exert influences on the vasomotor centers also. Raab(13) found that under the influence of oxygen shortage or perfusion with lactic acid the inhalation of carbon dioxide causes a considerably greater rise in blood pressure than occurs under normal conditions, therefore, he concluded that in essential hypertension it is possible that an accumulation of acid in the vasomotor centers due to some circulatory spasm 
may oocur.

Hill and Flack(14) state that either carbon dioxide excess or oxygen want exert an influence on blood pressure. Moderate carbon dioxide excess stimulates the vasomotor centers $10-25 \%$ above normal.

Whether or not the cerebral vessels have the power to constrict and relax has not been definitely decidod. Cobb(15) thinks that the cervical sympathetic has a definite control over the capillary bed of the brain. By the injection of Berlin blue under pressure equal to that of normal systolic pressure into the head arteries after section of the cervical sympathetic an increase in volume of the vessels on the homolateral side was found.

Forbes(16) working with the skull window preparation noted a change in the size of the pial vessels after stimulation of cervical sympathetics. Accurate account of spinal fluid, arterial and venous pressures was kept so as to eliminate the possibility of a passive influence. However, altho changes in the diameter of vessels were noted, they were not nearly so great as one would ordinarily expect in the systemic arterioles.

Indirect evidence of a nervous control of hypertension is abundant. Tuthill (17) observed the pathological changes in the vessels of the medulla oblongata in a series of patients with essential hypertension and normals; his conclusion was that there is no appreciable aifference in the two. Since the nervous system has control over the cir- 
culation one might expect some irregularity in the mechanism for the normal regulation of blood pressure. Just what this is no one has ever shown. Hering(6) and his pupils have shown that if the blood pressure restrainers (reflex paths from aorta and carotid sinus) are cut in the rabbit or dog arterial hypertension results. The longest experimental hypertension on record by this method is 1 I/2 years. At autopsy, besides cardiac hypertrophy arterial and renal lesions were observed, but these bore little similarity to those of essential hypertension. This experiment is important in that it shows chronic hypertension can be produced by a derangement of the vasomotor system. As Fishberg ${ }^{(18)}$ states, however, this experimental hypertension is unlike essential hypertension in that in the latter there is no irregularity of the blood pressure restrainers, for pressure on the carotid sinus produces slowing of the pulse and a drop in pressure of the same order as seen in health. Since the depressor reflexes are intact, one is made to think that the upset is beyond this. The question arises as to the effect which ischemia to the brain might produce by means of partial occlusions of the blood vessels.

These effects are conceived of as follows:-

(1) Firgt one might expect an elevation of blood pressure due to the lowering of pressure or change of the pulse wave in the crrotid sinus.

(2) Ischemia may also affect the nutrition of cells of the central nervous system in the various centers.

(3) Possibly sclerosis of vessels in important blood pressure controlling areas of the brain may result. 
(4) Secondarily, there may be an effect on the systemic arterioles due to the reflex rise in pressure as Hering and his school found.

The following experiments were devised to pro-

duce brain ischemia.

The carotid arteries below the carotid sinuses were sutured longitudinally for a short distance along their courses, so that the lumena could carry only a small quantity of blood. The vertebral on one side was completely closed while the other was left open. Eight animals were used. Pressure readings before operation were used as controls.

In the acute experiments the blood pressure rose 60 to $70 \mathrm{~mm}$. above the normal. Complete occlusion of carotias would cause somewhat higher pressures, but these could not be maintained due to the asphyxial condition produced. The rise was rapid, that is occurred in a few seconds. The fall was gradual over a period of about fifteen minutes when the normal level was reached.

In the chronic exoeriments the animals lived from one to four and a half months. Only two of these were followed to conclusion.

One of these which had the carotids only sutured developed an elevation of fourteen to sixteen $\mathrm{mm}$. of mercury extending over a period of four and a half months. (See Chart No. I). At this time the animal was killed. The post-mortem examination was negative. This hypertension was attributed to carotid sinus influence.

The other animal which had a greater brain ischemia produced by total occlusion of one vertebral artery in addition 
to partial occlusion of both carotids lived two months and then died in convulsions. The blood pressure rose 45 to 55 m.m. of mercury. (See Chart No. II). Just before death there was a marked drop in blood pressure apparently due to cardiovascular failure.

The post-mortem examination revealed edema of the brain with some degeneration of the nerve cells. This oonsisted essentially of shrinking and a condensation of the chromatin network. The walls of some of the arterioles were possibly slightly thickened. The liver was quite markedly damaged by acute passive congestion. There was slight cloudy swelling of the kidneys.

As has already been said hypertengion in all probability results from peripheral vascular sclerosis. The Iumena of the arterioles are reduced oy hyperplasia and hypertrohy in a great many cases. Ischemia, or the partial cutting off of the blood supply to a tissue, which results in an inadequate oxygen supply is, possibly, a cause for the intimal and medial changes of the arterioles.

The following experiment has been arranged to test the truth of this assumption as applied to the muscles. It consists of partial arterial occlusions. In acute experiments it was found that in five normal healthy dogs, even when the partial occlusions of femorals and brachials were done at such a point as to permit the least possible collateral circulation, that al tho the systemic pressure rose a few millimeters it soon aropped to normal in less than five minutes, due to splanchnic relaxation. 


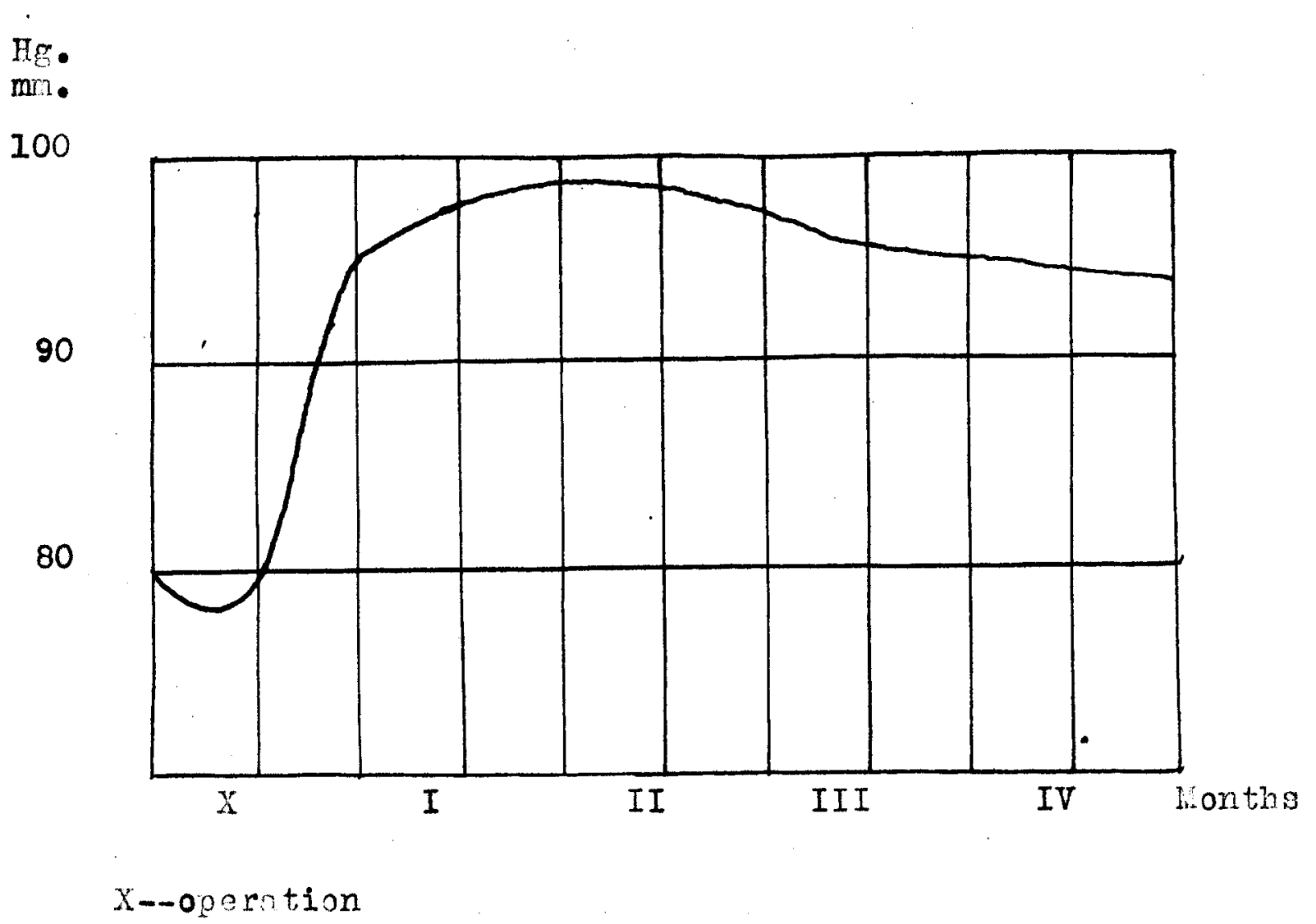

CHART I0. I. Blood pressure chart of dog with oth carotids partially occluded. 


\section{$\mathrm{H}$.}

mrne

145

135

125

115

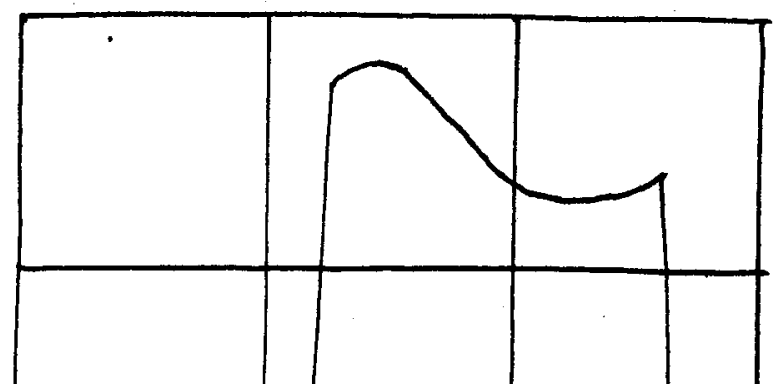

95

105

85

II Wonths

X--overation

CHAPIO II. II. Blood prossure chart of dog with oarotids partially occluded and one verteoral completely occludeả. 
In the chronic experiment the ischemia hypothesis was tested. One animal died prematurely and was discarded. One animal lived six months under laboratory conditions with partial occlusion of the arteries sup lying the tissues of three limbs, the vessels of one were left as a control and for the taking of blood pressures. During this time blood pregsure readings averaged about 90 systolic and 63 diastolic. The extremes were 92 to 84 systolic and 72 to 58 diastolic. The pressure readings were fairly irregular, but were attributed to normal variations. At autopsy stadies of the vessels of the muscles to which the vessels had been partially occluded and also of other muscles as well as all viscera were made. The walls of the arterioles in the muscles to which the vessels were partially occluded were slightly thicker than those of other muscles of the same animal or other aninals of the same estimated age. It could not be definitely determined whether or not this was due to hyperplasia, foreign material or just contraction.

In another group of six animals, the rensl arteries were similarly treated, that is, suturing about $2 \mathrm{cms}$. of the vessel walls so as to cut the blood flow down to about one-third. Pressur $\mathrm{s}$ before and after operation as a matter of routine were taken, and were not found to vary to any extent. During the time that the animal lived urinalyses were done to get some idea if any ki nney damage was produced. The anclygis consisted of total nitrogen, urea nitrogen, specific gravity, creatinin, qualitative albumin, total solids and quan- 
titative excretion. These revealed no abnormal renal function.

\section{SUMLIARY}

It is apparent that sudden occlusion of the renal arteries produced by suturing so as to partially occlude these vessels from a third to a half of their diameter does not cause sclerosis of the renal vessels or an elevetion of blood pressure either at once or over a period of several months.

If the main blood supply to three limbs is suddenIy occluded there is a sudden slight elevation of blood pressure which disappears in less than five minutes. If this blood supply is diminished over a period of several months by artial occlusion of the arteries ther is no elevation of blood pressure, but a questionable thickening of the walls of small arteries. This could be due to hyperplasia, products of degeneretion or contraction of the vessels. Further observations including a larger series of animals over a longer period of time should be made to elucidate this point.

If there is a sudden occlusion of the corotid arteries the systemic blood pressure rapidly rises and then gradually falls. If these vessels are pertially occluded by suturing over a short distence so es to occlude them to an extent of one-third or one-helf of the diameter of the lumena there will follow a definite and proloned rise of blood pressure which cannot be attributed to nerve cell changes or vascular sclerosis. 
1. Barwell \& Smith. Jour. Jlin. Invet. 7:1 '29.

2. N1gers: Circulation in Health \& Disease, D 116 '23.

3. Moore, Hamilton \& Kingman. (Personal connunic tion).

4. Austrian. Bull. Johns Hopking Hosp. 22:9 '1l.

5. Ko1th, Rountree \& Geraghty. Aroh. Int. Hed. 16:547'15.

6. Fishberg. Hypertension \& Nophritis, P 195, '31.

7. Heymans. Archives International, Vol. XI,Fasc.III, 292,'31.

8. Evans. Recent Adrances in Phys. Ch. z.

9. Florey, Marvin \& Drary. Jour. Phys. 65:204.'28. $64: 318,28$.

10. Nagh. Jour. Phys. 61:26 (proc.).

11. Starling. (Proc. Roy. Soc. Iond .) 97:463, '25.

12. Anrep \& Segall. Jour. Phys. 61:215, '26.

13. Rasb. Arch. Int. hed. 47:757, '31.

14. H1Il \& Flack. Jour. Phys. 37:102.

15. Cobb. Aroh. Noar. \& Phys., 21:1102,29\& Am. Jour. Hed. Sc., $178: 528,129$.

16. Forbes. Am. Jour. Liled. Sc., 178:528, '29.

17. Tuthill. Arch. 2ath. 11:760, '31.

18. Highberg. (Hypertension \& Nephritis) 31 